\title{
The Covid-19 Pandemic and Triggered Acute Myocardial Infarc- tion among Non-Infected Individuals
}

\author{
Ayman Hammoudeh, MD, FACC ${ }^{*}$ (D), Hadi Abu-Hantash, MD, FACC ${ }^{2}$, Ramzi Tabbalat, MD, FACC ${ }^{3}$, \\ Eyas Al-Mousa, MD, FACC ${ }^{1}$, Eyadeh Madanat, MD', Raad Al-Muhaisen, MD ${ }^{3}$, Mahmoud Fakhri, MD \\ and Imad A Alhaddad, MD, FACP, FACC ${ }^{4}$ (D)
}

${ }^{1}$ Department of Cardiology, Istishari Hospital, Jordan

${ }^{2}$ Department of Cardiology, Farah Medical Center, Jordan

${ }^{3}$ Department of Cardiology, Abdali Hospital, Jordan

${ }^{4}$ Department of Cardiology, Jordan Hospital, Jordan

*Corresponding author: Ayman Hammoudeh, MD, FACC, Department of Cardiology, Istishari Hospital, 44 Kindi Street, Outpatient Building \#1, 3 ${ }^{\text {rd }}$ Floor, Amman, Jordan, Tel: +962-500-1000

The Covid-19 pandemic has swept across the globe and caused an unprecedented morbidity and mortality in over 200 countries all over the world [1]. Clinical studies have extensively addressed the wide spectrum of acute cardiovascular complications in Covid-19 infected patients [2]. Individuals not infected with the virus, on the other hand, might be susceptible to sustaining acute myocardial infarction (AMI) triggered by the prolonged lockdown and its psychosocial stressors. In an ongoing study on acute cardiovascular events triggered by the Covid-19 lockdown and its associated psychosocial stressors, we report the first 55 cases of AMI.

We examined the exposure to various triggering events among adults who presented with AMI (including ST-segment elevation MI [STEMI] and non-ST-segment elevation MI [NSTEMI]) to 6 tertiary care centers in Amman, Jordan during the Covid-19 imposed lockdown period from March 4 through June 1, 2020. Patients were enrolled if they reported exposure to at least one Covid-19 lockdown-related triggering event. Data obtained from patients or their immediate family members included baseline clinical characteristics, prior atherosclerotic cardiovascular disease and revascularizations. Patients were enquired about the nature and severity of these triggering events during the lockdown, whether they were exposed to such triggering events in the past, and any prior diagnosis of psychological or psychiatric illness. The hospital course, coronary diagnostic and revascularization procedures, and complications were documented. None of the enrolled patients was infected with the Covid-19 virus.

As of June 1, 2020, 55 patients have been enrolled in the study including 19 (34.5\%) STEMI and 36 (65.5\%) NSTEMI patients. Patients were predominantly males $(45,81.8 \%)$ with a mean age of $63.7 \pm 9.8$ years. Hypertension was present in $32(58.2 \%)$ patients, cigarette smoking in 31 (56.4\%) and diabetes mellitus in 26 (47.3\%). Forty seven (94.0\%) patients had $\geq 2$ cardiovascular risk factors. Prior diagnosis of coronary artery disease or revascularization were reports by $26(47.3 \%)$ and 19 (34.5\%), respectively. None of the patients reported exposure to similar triggering events or significant vulnerability to stressful situations prior to the Covid-19 pandemic lockdown, history of psychological or psychiatric illness or being prescribed psychotropic medications. There were no healthcare workers among the enrolled patients. Of the whole group, 52 (94.5\%) patients underwent coronary angiography which revealed significant single or multivessel CAD in 50 (90.1\%) patients. Of those, coronary revascularization was performed in 41 (82.0\%) patients, including percutaneous coronary intervention ( $\mathrm{PCl}$ ) in 39 patients and coronary

Citation: Hammoudeh A, Abu-Hantash H, Tabbalat R, Al-Mousa E, Madanat E, et al. (2020) The Covid-19 Pandemic and Triggered Acute Myocardial Infarction among Non-Infected Individuals. Int J Clin Cardiol 7:185. doi.org/10.23937/2378-2951/1410185

Received: June 08, 2020; Accepted: June 16, 2020; Published: June 18, 2020

Copyright: (C) 2020 Hammoudeh A, et al. This is an open-access article distributed under the terms of the Creative Commons Attribution License, which permits unrestricted use, distribution, and reproduction in any medium, provided the original author and source are credited. 
Table 1: Triggering events patients were exposed to prior to the onset of acute myocardial infarction.

\begin{tabular}{|l|l|}
\hline Trigger & $\begin{array}{l}\text { Patients } \\
\text { N (\%) }\end{array}$ \\
\hline Lockdown stress, loneliness and isolation & $52(94.5 \%)$ \\
\hline $\begin{array}{l}\text { Financial stress and hardship, volatile income, } \\
\text { loss of job }\end{array}$ & $22(40.0 \%)$ \\
\hline Cigarette smoking binge & $15(27.3 \%)$ \\
\hline Anger & $12(21.8 \%)$ \\
\hline Fear of contacting the disease & $10(18.2 \%)$ \\
\hline Strenuous physical effort & $3(5.5 \%)$ \\
\hline Inability to attend funeral of a loved person & $3(5.5 \%)$ \\
\hline Heavy meals & $2(3.6 \%)$ \\
\hline Fear of lack of medical care & $2(3.6 \%)$ \\
\hline Hopelessness & $1(1.8 \%)$ \\
\hline
\end{tabular}

artery bypass graft surgery in 2 patients. The in-hospital course was event-free for 52 (94.5\%) patients. A male patient had cardiac arrest and died 6 hours after $\mathrm{PCl}$, a female is recovering from cardiogenic shock necessitating intra-aortic balloon support and hemodialysis, and a man with minor intracranial hemorrhage that was conservatively-managed.

The triggering events that preceding the onset of AMI are shown in Table 1 . The triggers most often reported were lockdown stress and loneliness in 52 (94.5\%), financial stress and hardship, volatile income, and loss of job in $22(40.0 \%)$, cigarette smoking binges in 15 (27.3\%), anger in $12(21.8 \%)$ and fear of contacting Covid-19 infection in 10 (18.2\%). Other triggers reported included death of a significant person, strenuous physical effort, heavy meals and fear of lack of medical care. Exposure to 2 or more triggering events was reported by 50 patients (90.1\%). All patients reported being exposed to these triggering events for variable durations of time ranging from 2 days to several weeks prior to presentation. None of the patients reported exposure to similar events prior to the Covid-19 pandemic lockdown.

Studies have consistently demonstrated the presence of triggered AMI in close association with natural large-scale disasters and events (i.e., earthquakes, hurricanes and snow blizzards) and man-made events (i.e., wars, missile attacks and terror events) and pandemics [3]. The Covid-19 pandemic and the associated measures of lockdowns, quarantine, and shutdown of almost all social and economic activities represent a global unparalleled medical and social challenge on a global level. Despite the fact that these measures may be critical to mitigate the spread of this disease, they undoubtedly have major short- and long-term consequences on mental health [4]. During the Covid-19 pandemic, individuals not infected with the virus might be exposed to a variety of triggering events that are directly related to the immense psychosocial stressors of the lockdown, and subsequently predisposing susceptible vulnerable individuals to acute cardiovascular events including AMI. Most of published studies that evaluated psychosocial stressors related to the pandemic have focused on mental and social health consequences in Covid-19-infected individuals [5]. However, published reports have not addressed the issue of triggered AMI among non-Covid-19 individuals. We have shown that Covid-19 pandemic-related lockdown and the accompanying stressors can potentially trigger AMI in vulnerable non-infected individuals. The great majority of our patients had more than one cardiovascular risk factor and about half of them had a preexisting cardiovascular disease. The clinical features of this group of patients, including mean age, gender distribution and prevalence of cardiovascular disease risk factors, were not different from those among patients with AMI enrolled in large scale studies [6].

Patients were exposed to a unique set of triggering events directly related to the Covid-19 pandemic for the first time in their entire lives. It is no surprise that lockdown stress, loneliness, isolation, financial hardships and anger were the most commonly reported triggering events to precede the onset of AMI, and that most of the patients reported exposure to at least two triggering events. Financial instability in the presence of lockdown is often associated with anger, frustration, fear, and hopelessness. The heavy emotional weight of such coexisting stressors may form a combustible mix and complex conglomerate with respect to triggering $\mathrm{AMI}$ $[7,8]$.

The stress-related pathophysiological changes that underlie triggering AMI include increased sympathetic activation and catecholamine surge with related increases in blood pressure, and oxygen demand, as well as pro-inflammatory and procoagulant responses leading to systemic vasoconstriction, increase in the coronary vascular tone and shear stress alteration. These changes may lead to disruption of an already vulnerable coronary atherosclerotic plaque and thrombus formation in a major epicardial coronary artery $[9,10]$.

The Covid-19 pandemic lockdown-associated stressors can trigger AMI in vulnerable individuals. This calls for implementation of timely and effective mental health screening and intervention programs to identify such individuals and mitigate the cardiovascular effect of these stressors.

The study is registered in clinicaltrials.gov (ID: NCT04368637).

\section{Authors Declaration}

All authors take responsibility for all aspects of the reliability and freedom from bias of the data presented and their discussed interpretation.

\section{Acknowledgement of Grant Support}

None. 


\section{Disclosure}

None of the authors have any conflict of interest to disclose.

\section{References}

1. Weiss P, Murdoch DR (2020) Clinical course and mortality risk of severe COVID-19. Lancet 395: 1014-1015.

2. Hendren NS, Drazner MH, Bozkurt B, Cooper LT Jr (2020) Description and proposed management of the acute COVID-19 cardiovascular syndrome. Circulation 141: 1903-1914.

3. Rogers EJ, Hsieh SF (2011) Triggers of myocardial infarction. Lancet 377: 2175-2176.

4. Galea S, Merchant RM, Lurie N (2020) The mental health consequences of COVID-19 and physical distancing: The need for prevention and early intervention. JAMA Intern Med.

5. Rubin GJ, Wessely S (2020) The psychological effects of quarantining a city. BMJ 368: 313.
6. Alhaddad IA, Tabbalat R, Khader Y, Al-Mousa E, Izraiq M, et al. (2017) Outcomes of middle eastern patients undergoing Percutaneous Coronary Intervention $(\mathrm{PCl})$ : The primary analysis of the first Jordanian PCl Registry (JoPCR-1). Heart Views 18: 3-7.

7. Mohammad MA, Karlsson S, Haddad J, Cederberg B, Jernberg T, et al. (2018) Christmas, national holidays, sport events, and time factors as triggers of acute myocardial infarction: SWEDEHEART observational study 1998-2013. BMJ 363: 4811.

8. Elfassy T, Swift SL, Glymour MM, Calonico S, Jacobs Jr DR, et al. (2019) Associations of income volatility with incident cardiovascular disease and all-cause mortality in a US cohort. Circulation 139: 850-859.

9. Kivimaki M, Steptoe A (2018) Effects of stress on the development and progression of cardiovascular disease. Nat Rev Cardiol 15: 215-229.

10. Smyth A, O'Donnell M, Lamelas P, Teo K, Rangarajan S, et al. (2016) Physical activity and anger or emotional upset as triggers of acute myocardial infarction: The INTERHEART Study. Circulation 134: 1059-1067. 